\title{
Individual Weight Estimation of Cynoglossus-gracilis Based on Measurement of Irregular Image Area
}

\author{
Ma Guoqiang, a , Tian Yunchen ${ }^{1,2, ~ b}$, Li Xiaolan ${ }^{1}$ \\ ${ }^{1}$ School of Computer \& Information Engineering, Tianjin Agriculture University, Tianjin 300384; \\ ${ }^{2}$ Tianjin Key Laboratory of Aquatic Ecology and Aquaculture, Tianjin 300384 \\ amgqwxj@163.com, bianyunchen@tjau.edu.cn
}

\section{Keywords: Aquaculture, Image processing, Area measurement}

\begin{abstract}
For aquaculture, the classification of live fish and the deconcentrition of fish into more ponds are very important process. Non-contact and no-harm are always the target of this process. Using the technology of digital image processing, the binary irregular image of Cynoglossus Gracilis is got and measurement; we analyze the relationship between the weight of fish and flat surface area by a linear regression model. The experimental results show that two parameters has a certain linear relationship, the correlation coefficient is $0.3807\left(\mathrm{R}^{2}=0.1450\right)$. Further research is needed to account for the effects of different growth stages of Cynoglossus gracilis body thickness and other factors, a more accurate model to identify the relationship between the two parameters, to provide support for the non-contact measurement of weight and classification.
\end{abstract}

\section{Introduction}

Nowadays, aquatic products have become an indispensable daily food. At the same time, factory farming has become an important production mode of aquaculture. In the development of factory farming, visual quality detection is mainly based on measurement of size and shape.

In recent years, the aquatic products measurement via image processing and computer vision technology have been pay attention to by many researchers to detect quality. The measure parameters include size, shape, area, and color parameters. Many scholars have studied the relationship between the length and the weight of different fish [1-3]. The classical mathematical model is $\mathrm{W}=\mathrm{aL}^{\mathrm{b}}[4]$. In addition to length, some other parameters also embody the differences of visual quality, such as area, shape, and so on. The relationships of thus parameters have been studied by many researchers. Liang and Chiou captured projected images of Taiwan tilapia and derived relationships of weight-length, weight-height, weight-perimeter and weight-area of 50 samples. The result showed that tilapia's weight was more closely related to its area $\left(R^{2}=0.9303\right)$ [5]. In another research of 170 herring(C.harengus) by Mathiassen et al., analysis results showed that a similar correlation between area and weight was obviously, with $\mathrm{R}^{2}$ values of between 0.919 and 0.938 [6]. In 2011, Zhang et al. extracted the axis and the projected area of freshwater fish (Crucian carp) through gray, binary conversion images. The belly and the tail were established, which were used to correct the projected area. From 76 fishes, the researchers found that relationship between the weight and the projected area $\left(\mathrm{R}^{2}=0.9878\right)$ [7]. About another specific quality evaluation of fish, Rekratn and Kaewpoonsuk proposed a new machine vision system to calculate area of fish filet and fish bone. The major steps of this system was using Ultraviolet lamp [8].

The objective of this study was to found out the relationship between the weight and full-body area of the Cynoglossus gracilis. This area was irregularly, so using image processing technology to measure this irregularly area was another content of this research. Using electronic balance to get the weight of each fish, and then analysis the relationship between weight values and fish's full-body area values with simple linear regression model and second-order polynomial model. As a result, the Cynoglossus gracilis' weight was more closely related to its full-body area $\left(\mathrm{R}^{2}=1450\right)$ with the linear regression model and second-order polynomial model. 


\section{Materials and Methods}

Algorithms and Methods. The general steps of image measurement include original image acquisition, image enhancement, image restoration, image segmentation, projected-area extraction, and projected-area measurement.

Image conversion refers to calculate the gray value of a grayscale image's pixels from the RGB values of a true-color image. Similarly, a classical function is written as:

$$
\text { Gray }=R \times 0.299+G \times 0.587+B \times 0.114
$$

There are many methods of image enhancement. Linear gray scale transformation is the most commonly used method of image enhancement.

It is assumed that the original image $\mathrm{f}(\mathrm{x}, \mathrm{y})$ in the gray range of $[\mathrm{a}, \mathrm{b}]$, after linear transformation, the output image of the gray scale of $[\mathrm{c}, \mathrm{d}]$, then the linear transformation formula can be expressed as:

$$
g(x, y)=\frac{d-c}{b-a}[f(x, y)-a]+c
$$

If the gray scale of the digital image is $0 \sim \mathrm{M}$, but most of the pixel gray value falls in range [a,b] ,only a very small part of the gray value of the pixel is not in this range, formula (2) will change to (3):

$$
g(x, y)=\left\{\begin{array}{cl}
c & 0 \leq f(x, y)<a \\
\frac{d-c}{b-a}[f(x, y)-a]+c & a \leq f(x, y)<b \\
d & b \leq f(x, y)<M
\end{array}\right.
$$

Threshold method is a simple and effective method of image segmentation. The method uses one or several thresholds to divide the gray level of the image into several parts, each part is treated as an area. here.

A typical algorithm of threshold method is Otsu's method. It's basic idea is familiar, not repeat

Image binarization is refers to define the pixels values of a gray image with 1 or 0 , threshold $\mathrm{T}$ as boundary. For example, all pixels is determined as belonging to a particular object, which gray value is greater than the threshold, and these pixels are assigned to 0 (black) as the region of interest. The rest of the pixels of this image are assigned to 255 (white), as the background.

The formula (13) can be used to convert the gray image to binarization image.

$$
\mathrm{t}(\mathrm{x}, \mathrm{y})=\left\{\begin{array}{cc}
255 & \mathrm{~g}_{\min } \leq \mathrm{g}(\mathrm{x}, \mathrm{y}) \leq \mathrm{T} \\
0 & \mathrm{~T}<g(x, y) \leq \mathrm{g}_{\max }
\end{array}\right.
$$

Calculation of irregular image area, a simple and effective method is with the help of a single pixel represents the area. In the same camera view of the projected thing, a standard object is placed. Through the total pixels and the known area of this standard object, one pixel represent how many area can be calculate out. And then, the projected thing's area is the product of the total pixels of this projected thing and the area of one pixel represented. Normally, a coin is used as a standard object. Its diameter is $25 \mathrm{~mm}$, the area is $4.91 \mathrm{~cm}^{2}$.

$$
\begin{aligned}
& S_{\text {each pixel's area }}=A_{\text {The area of a standard object }} / C_{\text {The total pixels of this object }} \\
& S_{\text {projected thing }}=C_{\text {The total pixels of the projected thing }} \times S_{\text {each pixel's area }}
\end{aligned}
$$

As described above, the calculation process of the irregular image area can illustrated in Fig. 1.

Regression analysis is a statistical analysis method, which is used to determine the quantitative relationship between two or more variables. We analyzed these weight and area data by using, linear function, polynomial function, logarithmic function and power function model.

Linear function: $y=a x+b$

Polynomial function: $y=a x^{2}+b x+c$

Logarithmic function: $y=a \ln (x)+b$

Power function: $\mathrm{y}=\mathrm{ax}$ 


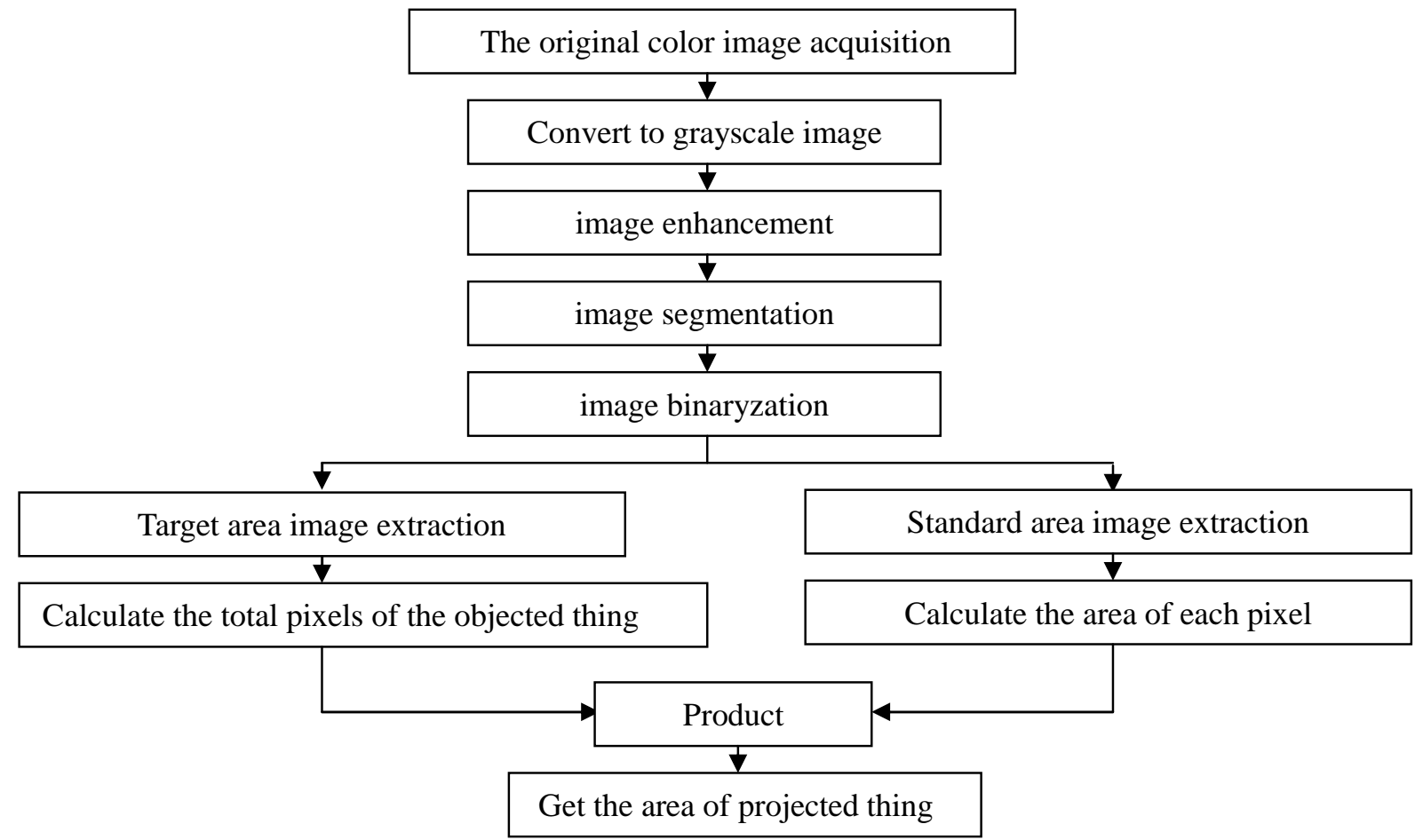

Fig. 1 Flow chart of irregular image area's calculation.

\section{Hardware System}

The experimental hardware system consisted of a Web camera (Aoni, D881HD720P, USB 3.0 port), a personal computer (4GB memory, inter core i5 chip). Use white acrylic panels as a bottom plate of a triangular frame; use Windwos7 system comes with ECap (1.0.1.4) of video capture software as the image acquisition software. Image acquisition hardware as shown in Fig. 2.

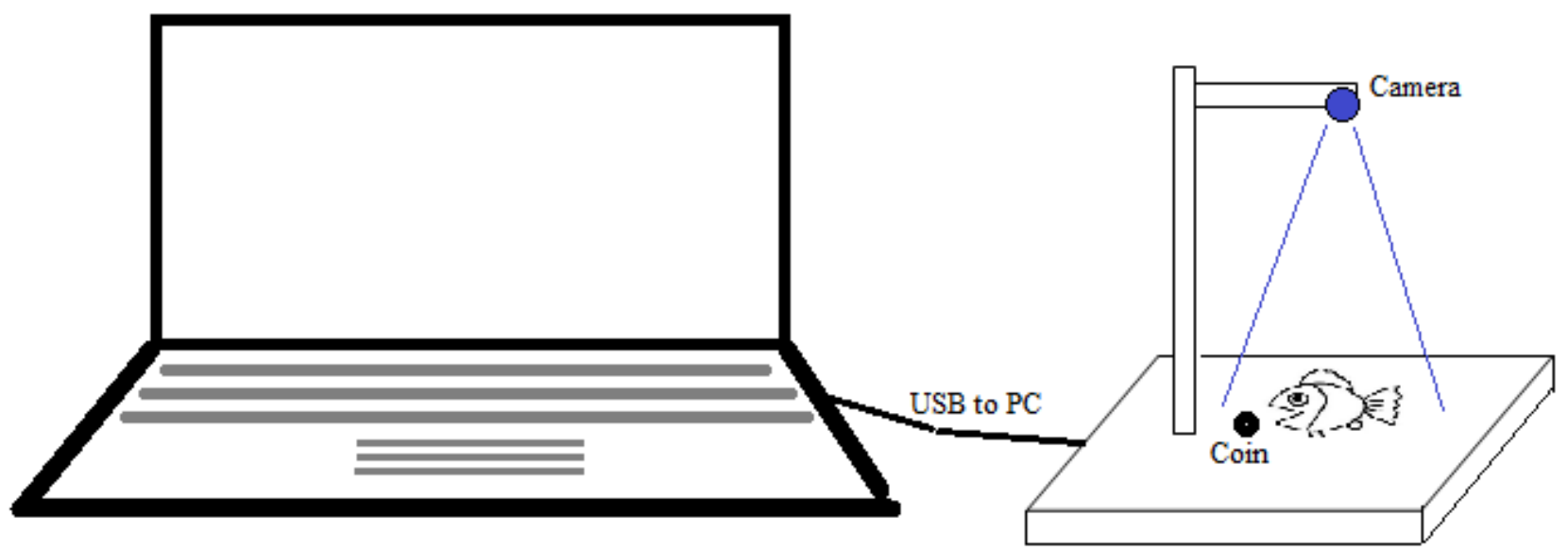

Fig. 2 Hardware system of image acquisition.

Software Programming. The Matlab's Image-processing ToolBox and Computer-vision Toolbox provide a large number of related functions. In this paper, the image processing program was based on the toolbox function. The image processing functions are used to have the image enhancement function imadjust(), the global threshold calculation function graythresh(), the image binary function $\operatorname{im} 2 b w()$, the target region image pixel point calculation function numel () and find (), et al. With the use of various functions that refer to the MATLAB help file, not repeat them here.

Fish. 50 fresh Cynoglossus-gracilis were provided by a super market as experiment object. Their weight were measured with a electronic balance which accuracy is $0.1 \mathrm{~g}$ and model is TD6001, product by Tianjin Electronic Balance Instrument Factory. 


\section{Results}

The various experiment carried out on the above said imagery in Matlab R2015b. The images processing results, weight and area values are shown on Fig. 3 and Table 1.

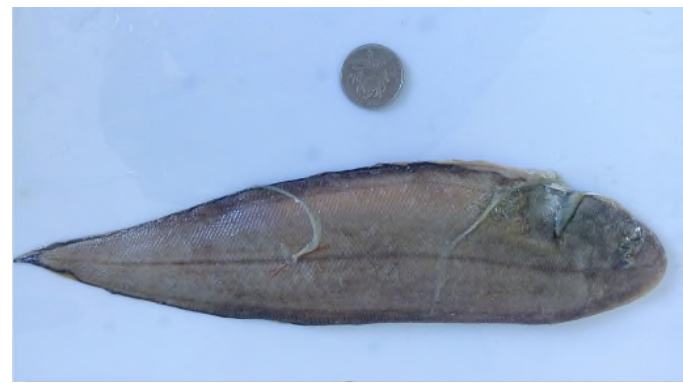

(a) original true color image

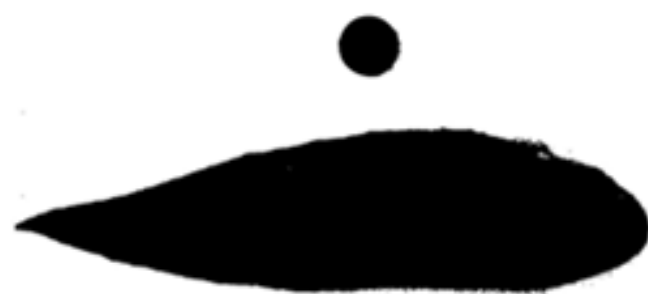

(b) binary image

Fig. 3 Image processing results.

Table 1. One-Yuan Coin, Cynoglossus Gracilis’s Flat Surface Area and Pixel Count (Part).

\begin{tabular}{rccc|cc}
\hline \multicolumn{3}{c|}{ Cynoglossus Gracilis } & \multicolumn{2}{c}{ One-Yuan Coin } \\
\hline ID & Weight $(\mathrm{g})$ & Area $\left(\mathrm{mm}^{2}\right)$ & Pixels & Area $\left(\mathrm{mm}^{2}\right)$ & Pixels \\
\hline 1 & 94.4 & 10199.71591 & 2866900 & 490.87 & 137972 \\
2 & 93.0 & 10535.05889 & 2266217 & 490.87 & 105592 \\
3 & 104.4 & 12200.56891 & 2619020 & 490.87 & 105372 \\
4 & 119.6 & 11995.90543 & 2439846 & 490.87 & 99838 \\
5 & 104.4 & 11278.96866 & 2688644 & 490.87 & 117012 \\
6 & 117.2 & 12265.41786 & 2851278 & 490.87 & 114110 \\
7 & 143.7 & 11865.07197 & 3118754 & 490.87 & 129026 \\
8 & 132.2 & 13546.28344 & 3100216 & 490.87 & 112341 \\
9 & 116.2 & 10008.69918 & 2905779 & 490.87 & 142512 \\
10 & 129.0 & 10228.2346 & 2474138 & 490.87 & 118738 \\
\hline
\end{tabular}

The relationship between the weight and the area are shown on Fig. 4.

The experimental results show that the correlation coefficient $\left(\mathrm{R}^{2}\right)$ of the power function model is the biggest value. The correlation coefficient $\left(\mathrm{R}^{2}\right)$ of the power function model is equal to 0.152 . The power function model is $y=2.321 x^{0.419}$. The other 3 correlation coefficients of linear function, polynomial function, logarithmic function are equal to 0.145 .

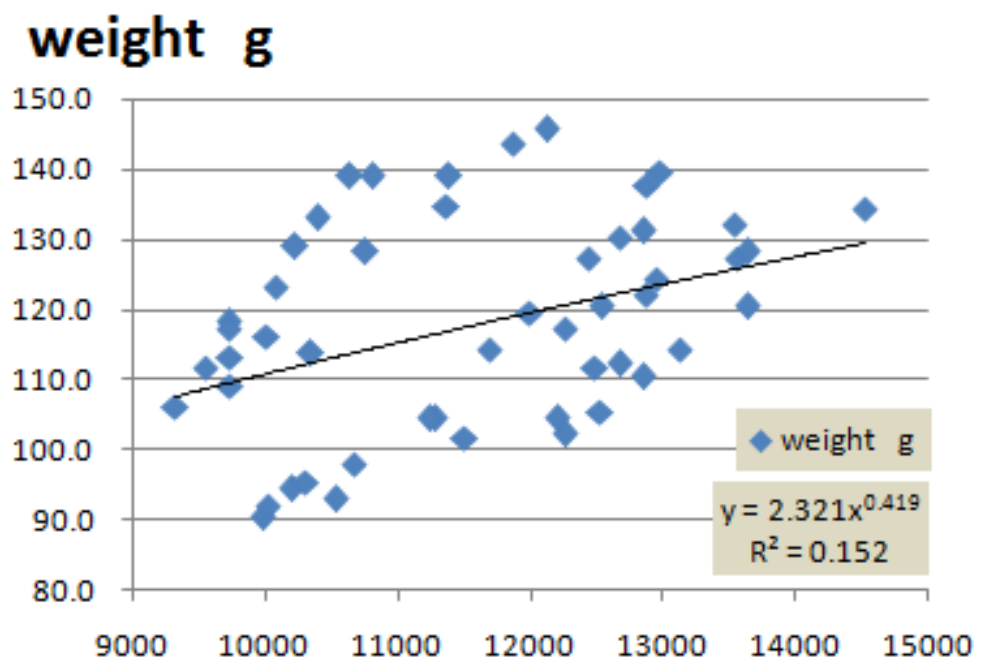

Fig. 4 Relationship of Cynoglossus gracilis's Body Weight and Body Flat Surface Area. 


\section{Discussion and Conclusion}

From the above experimental results, it show that there was a certain relationship between the Cynoglossus gracilis' weight and flat surface area $\left(\mathrm{R}^{2}=0.152\right)$. Because of the fewer samples, so the relationship was not very accurate. In addition, the experimental objects should be chosen in different growth stages of fish. In order to find out the relationship between the weight and flat surface area of Cynoglossus gracilis' full-life, this fish in different growth stages are needed.

Further research is needed to account for the effects of different growth stages of Cynoglossus gracilis body thickness and other factors, a more accurate model to identify the relationship between the two parameters, to provide support for the non-contact measurement of weight and classification.

\section{Acknowledgements}

This study was performed with financial support from the Science and Technology Support Key Projects of Tianjin City of China (14ZCZDNC00009), the Special Scientist Research of Public Welfare Industry (Agriculture) of China's Ministry of Agriculture (201203017), and Tianjin city science and technology major projects and engineering application integration, key technologies of precision control and monitoring management of freshwater aquaculture (15ZXHLNC00080).

\section{References}

[1] H. Aguirre, F. Amezcua, J. Madrid-Vera, C. Soto, Length-weight relationship for 21 fish species from a coastal lagoon in the southwestern Gulf of California. J. Appl. Ichthyol, 24(1) (2008) 91-92.

[2] C. I. de Ciencias Marinas, B. de Matanchen, Length-weight relationship of demersal fish from the Eastern coast of the mouth of the Gulf of California. J. Fish. Aquat. Sci, 5(6) (2010) 494-502.

[3] R. Froese, Length-weight relationships for 18 less-studied fish species. J. Appl. Ichthyol, 14(1-2) (1998) 117-118.

[4] B. Zion, The use of computer vision technologies in aquaculture - a review. Comput. Electron. Agric. 88 (2012) 125-132 (Review).

[5] Y. T. Liang, Y. C. Chiou, Machine vision-based automatic raw fish handling and weighing system of Taiwan tilapia. In: Chien, B. C., Hong, T. P., Chen, S. M., Ali, M. (Eds.), Next-Generation Applied Intelligence, vol. 5579. Springer, Berlin, Heidelberg, 2009, pp. 711-720.

[6] J. R. Mathiassen, E. Misimi, B. Toldnes, M. Bondø, S. O. Østvik, High-speed weight estimation of whole herring (Clupea harengus) using 3D machine vision. J. Food Sci. 76(6) (2011) E458-E464.

[7] Z. Zhang, Z. Niu, S. Zhao, J. Yu, Weight grading of freshwater fish based on computer vision. Trans. Chin. Soc. Agric. Eng, 27(2) (2011) 350-354.

[8] A. Rerkratn, A. Kaewpoonsuk, System development for quality evaluation of fish fillet using image processing. In: Paper presented at the 2014 International Conference on Computer, Communications and Information Technology (CCIT2014). 